\title{
A Formação no Pacto Nacional pela Alfabetização na Idade Certa (PNAIC)
}

\author{
The Training in the National Pact for Literacy at the Right Age (PNAIC)
}

\author{
Tascieli FELTRIN \\ Universidade Federal de Santa Maria \\ tascifeltrin@gmail.com \\ Suyan Barcellos DUTRA \\ Universidade Federal de Santa Maria \\ susssubarcel.dutra@hotmail.com \\ Helenise Sangoi ANTUNES \\ Universidade Federal de Santa Maria \\ professora@helenise.com.br
}

\begin{abstract}
Resumo: O presente artigo objetiva apresentar uma avaliação do programa Pacto Nacional pela Alfabetização na Idade Certa (PNAIC), através da experiência dos professores formadores do programa, da região central do Rio Grande do Sul. Nesse sentido, convidamos os professores formadores da cidade de Santa Maria - RS, a qual é responsável pela formação de todos os professores participantes do PNAIC na região central do estado a realizarem uma autoavaliação de sua atuação no programa, como também, a auto avaliar os efeitos e aspectos do PNAIC. A seguir apresentamos um breve histórico do programa de formação continuada e sua relação com a Universidade Federal de Santa Maria - RS desde sua criação com destaque para as atividades e peculiaridades de suas ações no cenário nacional. Em seguida contextualizamos as respostas e percepções dos professores formadores com as perspectivas contemporâneas de continuação do programa. Para o delineamento desta pesquisa, utilizamos como instrumento de coleta de dados um questionário semiestruturado através da ferramenta Google Docs. Inicialmente buscamos conhecer o histórico do programa PNAIC, e em seguida investigamos como os professores formadores avaliam o trabalho realizado, destacando os aspectos positivos, negativos e impactos do programa em suas trajetórias e na educação básica como um todo. Através das respostas apresentadas, foi possível, por exemplo, conhecer quais as fragilidades e pontos a serem reestruturados para as próximas edições.
\end{abstract}

Palavras-chave: PNAIC; Formação Continuada; Autoavaliação.

Abstract: This article aims to present an evaluation of the National Pact for Literacy at the Right Age (PNAIC) program, through the experience of the teachers who form the program, from the central region of Rio Grande do Sul. In this sense, we invited the teachers of the city of Santa Maria - RS, which is responsible for the training of all teachers participating in the PNAIC in the central region to carry out a self - assessment of their performance in the program, as well as to self - evaluate the effects and aspects of the PNAIC. Following is a brief history of the continuated education program and its relationship with the Federal University of Santa Maria - RS since its creation, highlighting the activities and peculiarities of its actions in the national scenario. Next, we contextualize the responses and perceptions of the teacher trainers with the 
contemporary perspectives of continuation of the program. The structure of this research used as data collection instrument a semistructured questionnaire through the Google Docs tool. Initially, we sought to know the history of the PNAIC program, and then investigated how the teacher trainers evaluate the work done, highlighting the positive, negative sides and impacts of the program on their trajectory and on education as a whole. Through the answers presented, it is possible to know the fragilities and points to be restructured for the next editions.

Keywords: PNAIC; Continuated Education; Self-evaluation.

\section{Introdução}

O Pacto Nacional pela Alfabetização na Idade Certa - PNAIC - é um programa criado em 2013 pelo Ministério da Educação (MEC) a fim de corrigir os altos índices de analfabetismo entre as crianças do ensino fundamental. Para tanto, o PNAIC mobiliza as esferas federais, estaduais e municiais em um compromisso formal pela alfabetização de todas as crianças até o final do terceiro ano do fundamental aos oito anos de idade.

Após sua criação o PNAIC passou por algumas atualizações em sua estrutura, como a estabelecida pela Resolução CD/FNDE n 10, de 4 de dezembro de 2015, a qual estabelece critérios e protocolos para nortear a assistência financeira no que tange à impressão dos materiais de formação. A Portaria $n^{\circ} 279$, de 6 de março de 2017 que estabelece indicadores e parâmetros para a concessão de assistência financeira através de edital do MEC. E, com destaque a Portaria $n^{\circ} 826$, de 7 de julho de 2017 que inclui a alfabetização em Língua Portuguesa e Matemática e a realização de avaliações pelo INEP1.

Pode-se definir os objetivos do Pacto da seguinte maneira:

- $\quad$ Garantir a alfabetização em Língua Portuguesa e Matemática até o terceiro ano do fundamental;

- Reduzir a distorção idade-série na educação básica; melhorar os Índices de Desenvolvimento da Educação Básica (IDEB);

- Contribuir para o aperfeiçoamento do desempenho dos professores.

${ }^{1}$ Instituto Nacional de Estudos e Pesquisas Educacionais Anísio Teixeira. 
A parceria entre união, estados e municípios visa a oferta de formação continuada na modalidade presencial aos professores alfabetizadores e seus orientadores de estudos (formadores) como também materiais didáticos, literários e pedagógicos que ofereçam apoio aos alfabetizadores. O presente estudo busca realizar uma avaliação do PNAIC a partir da percepção e da experiência de seus professores formadores. Nesse sentido, convidamos os professores formadores da cidade de Santa Maria - RS para responderem um breve questionário semiaberto a respeito de sua atuação no programa e auto avaliar os efeitos e aspectos do PNAIC, através da ferramenta Google Docs. A seguir apresentamos um breve histórico do programa de formação continuada e em seguida contextualizamos as respostas e percepções dos professores formadores com as perspectivas contemporâneas de continuação do programa.

\section{Formação continuada um investimento para as instituições de ensino}

Temos o conhecimento que em diferentes escolas, os profissionais designados para ensinar as crianças a ler e escrever (lecto-escrita), muitas vezes não tiveram uma formação voltada para o letramento. Nossa intenção com a presente escrita é salientar o quanto é importante que os professores sejam liberados pelas suas instituições de ensino, para que possam contribuir e aprender com seus colegas de profissão, assim como também com os orientadores de estudo (em um próximo momento iremos falar como ocorre a formação desses sujeitos).

Compreendemos que muitos profissionais que desenvolvem seus trabalhos no ciclo de alfabetização não têm um suporte teórico para esse determinado trabalho. Alguns não tiveram a oportunidade de concluir um curso superior, desse modo, se deparam com muitas dificuldades no processo de ensino-aprendizagem. Professores que já concluíram sua formação inicial também passam pelas mesmas dificuldades, assim ressaltamos o quanto é importante que esses profissionais participem do curso presencial do PNAIC, uma vez que ele é baseado no Programa Pró-letramento².

\footnotetext{
2 Mobilização pela Qualidade da Educação - é um programa de formação continuada de professores para a melhoria da qualidade de aprendizagem da leitura/escrita e matemática nos anos/séries iniciais do ensino fundamental. O programa é realizado pelo $\mathrm{MEC}$, em parceria com universidades que integram a Rede Nacional de Formação Continuada e com adesão dos estados e municípios. Podem participar todos os professores que estão em exercício, nas séries iniciais do ensino fundamental das escolas públicas.
} 


\section{Formação oferecida pelo PNAIC}

Os cursos desenvolvidos têm como seu objetivo proporcionar debates sobre a aprendizagem dos alunos que estão inseridos no ciclo de alfabetização, esse trabalho é desenvolvido entre universidade, secretarias da educação e escolas. O curso está organizado em oito unidades, com totalidade de 80 horas, tendo também um seminário de encerramento de 8 horas a 32 horas de estudos com atividades, com uma carga horária de 120 horas.

Os encontros são conduzidos por orientadores de estudo, esses são vinculados às secretarias municipais e estaduais de educação, sendo professores das redes. Para poderem participar do PNAIC, fazem um curso específico ministrado por universidades públicas totalizando 200 horas de curso. Os professores alfabetizadores recebem o valor de 200 reais mensais, por participarem do curso que tem a duração de dois anos. São disponibilizados aos professores os materiais utilizados durante o curso: livros, jogos pedagógicos e materiais que englobem a alfabetização.

A formação continuada do PNAIC tem princípios contidos na Resolução $n^{\circ}$ 2/2015. Art 16, do Conselho Nacional de Educação (CNE):

I. Os sistemas e as redes de ensino, o projeto pedagógico das instituições de educação básica,
bem como os problemas e os desafios da escola e do contexto onde ela está inserida; II. A
necessidade de acompanhar a inovação e o desenvolvimento associados ao conhecimento, à
ciência e à tecnologia; III. O respeito ao protagonismo do professor e a um espaço-tempo que
lhe permita refletir criticamente e aperfeiçoar sua prática; IV. O diálogo e a parceria com atores
e instituições competentes, capazes de contribuir para alavancar novos patamares de qualidade
ao complexo trabalho de gestão da sala de aula e da instituição educativa. (BRASIL, Resolução
$\left.n^{\circ} 2 / 2015\right)$.

Desse modo, a intenção é que durante o curso ocorra oficinas relacionando teoria e prática, proporcionando que os professores tenham reflexões do seu contexto educacional, e possam adotar novas práticas pedagógicas em suas respectivas escolas.

O MEC disponibiliza para as escolas participantes os livros didáticos que englobam do primeiro ao terceiro ano do Ensino Fundamental, Cadernos de 
Formação, livros do Programa Nacional do Livro Didático (PNLD), além dos jogos pedagógicos do PNAIC.

Para que ocorra uma avaliação de como os professores estão desenvolvendo seu trabalho, existe a aplicação da Provinha Brasil, que ocorre no início e no final do segundo ano do Ensino Fundamental. Anualmente, o INEP aplica uma avaliação das crianças que terminam o ciclo de alfabetização, essa é uma forma do governo verificar como está a qualidade da aprendizagem das crianças inseridas no ciclo de alfabetização, o resultado das provas mostraram o desempenho de cada professor, é dessa forma que esse profissional é avaliado.

Os alunos que estão no terceiro ano do Ensino Fundamental participam da Prova Avaliação Nacional da Alfabetização (ANA), que é uma avaliação externa, ela avalia o processo de aprendizagem desse grupo de alunos que estão no final do ciclo de alfabetização, com o objetivo de conhecer os níveis de alfabetização e letramento em Língua Portuguesa e Matemática das escolas públicas, mostrando o desempenho em leitura, matemática e escrita.

\section{Professores que participam do PNAIC no Rio Grande do Sul}

Essa formação está sendo desenvolvida na Universidade Federal de Santa Maria (UFSM) e na Universidade Federal de Pelotas (UFPEL). Entre 2012/2013, na área que engloba Alfabetização e Linguagem, participaram 8.600 professores alfabetizadores da rede pública municipal e estadual do RS, sendo que 541 professores eram orientadores de estudo e 20 eram formadores. No ano de 2014, a área de Alfabetização Matemática contemplou 8.143 professores, tendo 552 professores orientadores e 42 professores formadores. Em $2015^{3}$ participaram 8.143 professores alfabetizadores, nesse ano ocorreu um trabalho interdisciplinar, sendo que 546 eram orientadores de estudos e 20 professores formadores.

Os professores em formação como já havíamos comentado recebem $R \$ 200$, já os professores orientadores recebem $R \$ 765$, esse é o valor recebido pelos coordenadores também. Os formadores das instituições de educação superior

${ }^{3}$ Dados disponíveis no site: http://coral.ufsm.br/pactonacional/index.php/sobre 
recebem $R \$ 1,1$ mil, para desenvolverem os cursos e materiais necessários nas oficinas. O supervisor em cada instituição recebe $R \$ 1,2$ mil. Ocorre também um pagamento mensal para o coordenador-adjunto de $R \$ 1,4$ mil, além de $R \$ 2$ mil para o coordenador-geral.

A Portaria $n^{\circ}$ 90, de 6 de fevereiro de 2013, que fixa os valores das bolsas, foi publicado no Diário Oficial da União desta quinta-feira, 7, seção 1, página 6. As regras do pacto foram estabelecidas pela Portaria $n^{\circ} 867$, de 4 de julho de 2012, publicada no Diário Oficial da União de 5 de julho de 2012, seção 1, páginas 22 e 23.

\section{Autoavaliação: perspectivas sobre a formação no PNAIC}

Os resultados apresentados a seguir, foram construídos com base na aplicação de um questionário através da ferramenta Google Docs, metodologia utilizada para facilitar o acesso ao questionário e preservar as identidades dos formadores, oferecendo-Ihes a possibilidade de total sinceridade na redação de suas respostas, algo que pela natureza da pesquisa é fundamental para que se alcancem os objetivos propostos.

A cidade de Santa Maria, sede da Universidade Federal de Santa Maria é reconhecido polo educacional da região central do Rio Grande do Sul e referência na formação inicial e continuada de professores. Na referida cidade atuam nove professores formadores, os quais responderam as seis questões descritas na tabela a seguir (tabela 1). O questionário foi organizado de maneira mista com perguntas de múltipla escolha e dissertativas. A abordagem das respostas utilizouse de métodos quali-quantitativos de análise.

Tabela 1. Questionário aplicado.

\begin{tabular}{|c|l|l|l|}
\hline Questão & Tipo & Conteúdo & Opções \\
\hline 1 & $\begin{array}{l}\text { Múltipla } \\
\text { Escolha }\end{array}$ & $\begin{array}{l}\text { Como você avalia sua } \\
\text { aprendizagem? }\end{array}$ & $\begin{array}{l}\text { Ótimo/ Bom/ } \\
\text { Regular/Insuficiente }\end{array}$ \\
\hline 2 & Dissertativa & $\begin{array}{l}\text { A quanto tempo você participa do Programa Pacto } \\
\text { Nacional? }\end{array}$ \\
\hline
\end{tabular}




\begin{tabular}{|c|l|l|l|}
\hline 3 & Dissertativa & \multicolumn{2}{|l|}{$\begin{array}{l}\text { Na sua opinião qual a relevância do Programa para } \\
\text { os professores que participam? }\end{array}$} \\
\hline 4 & $\begin{array}{l}\text { Múltipla } \\
\text { Escolha }\end{array}$ & $\begin{array}{l}\text { Como você avalia a } \\
\text { estrutura e organização do } \\
\text { programa? }\end{array}$ & Regular/Insuficiente \\
\hline 5 & Dissertativa & $\begin{array}{l}\text { O Pacto na sua opinião, ajuda os professores a se } \\
\text { sentirem sensibilizados para repensar a atuação na } \\
\text { escola, bem como, reformular as atividades, se } \\
\text { adequando as reais necessidades propostas pelo } \\
\text { programa. }\end{array}$ \\
\hline 6 & Dissertativa & $\begin{array}{l}\text { Quais suas maiores dificuldades em participar do } \\
\text { Programa Pacto Nacional? }\end{array}$ \\
\hline
\end{tabular}

Foi disponibilizado um período de 30 dias para os participantes retornarem com suas respostas. Dos nove professores formadores, um se desligou do programa por motivos pessoais, um não respondeu e sete participaram. A seguir busca-se apresentar uma análise quali-quantitativa das respostas apresentadas.

Ao serem questionados sobre a qualidade do programa e convidados a avaliálo, todos os participantes classificaram o Pacto Nacional como ótimo, conforme gráfico abaixo.

\section{Gráfico 1: respostas dos participantes referente à questão 01}
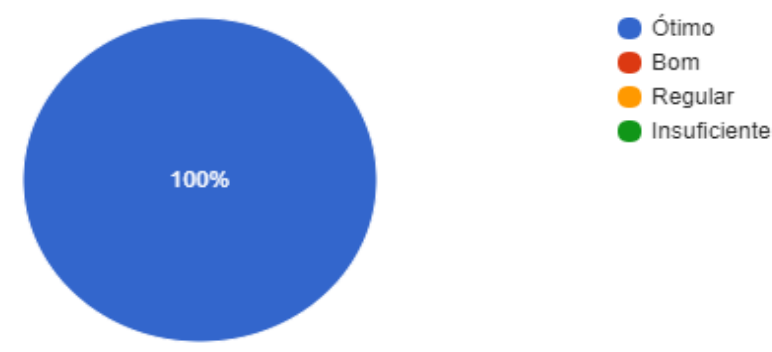

Um dado bastante importante saber que os professores formadores, envolvidos com o Pacto Nacional de Alfabetização e que conhecem toda a estrutura do programa 
o avaliam como ótimo, ou seja, reconhecem a importância desse mecanismo para a educação pública nacional e nesse sentido, consideram válida sua continuidade.

A seguir o questionário indaga a respeito do tempo de atuação dos formadores. Todos os formadores participam a no mínimo dois anos do programa, sendo que, quatro formadores participam a quatro anos, um participa a três anos, um apenas a dois anos, e um dos formadores afirma participar a cinco anos, desde dezembro de 2012. Sua permanência no programa indica que realmente estão satisfeitos com o mesmo e com sua atuação junto aos professores alfabetizadores, confirmando, de certa forma, a avaliação realizada na questão anterior (01).

No questionamento seguinte (03), solicitamos aos participantes que definissem qual a relevância do programa para os professores que participam. As respostas foram bem variadas, no entanto, todas apontam para uma avaliação extremamente positiva do mesmo. Conforme tabela 2 a seguir.

Tabela 2: Respostas referentes a questão 03.

\begin{tabular}{|c|c|}
\hline $1 \quad$ Participante & É muito importante. \\
\hline $2 \quad$ Participante & $\begin{array}{l}\text { É um programa que atualizou professores em serviço, } \\
\text { priorizando a qualidade da Educação. }\end{array}$ \\
\hline Participante & $\begin{array}{l}\text { Fundamental pela possibilidade de formação entre pares que o } \\
\text { programa possibilitou }\end{array}$ \\
\hline Participante & $\begin{array}{l}\text { Grande relevância. Em } 32 \text { anos de magistério foi a formação } \\
\text { mais significativa que participei. }\end{array}$ \\
\hline Participante & $\begin{array}{l}\text { Acredito ser o melhor programa de formação continuada/em } \\
\text { serviço que já houve no Brasil. }\end{array}$ \\
\hline Participante & Fundamental \\
\hline $7 \quad$ Participante & $\begin{array}{l}\text { Ter momentos de estudo, acesso à teoria, reflexão sobre a } \\
\text { prática e compartilhamento de conhecimentos. São momentos } \\
\text { ímpares de formação que promovem, efetivamente, mudanças } \\
\text { no fazer docente e melhoria na aprendizagem dos educandos }\end{array}$ \\
\hline
\end{tabular}

Os participantes em sua maioria destacam como ponto mais relevante do programa em relação a outros relacionados à formação continuada sua relação com a prática docente. Além disso é visível nas respostas a admiração dos professores 
com a completude do programa. Nessa lógica, o Caderno $n^{\circ} 10$, Integrando Saberes do Pacto Nacional de Alfabetização na ldade Certa, defende uma concepção de formação continuada que vai além de uma compensação das deficiências possíveis de uma má formação inicial, e que se coloca como um embasamento que envolve a prática docente e a partir desta constrói seus significados e novos saberes que embasaram as práticas futuras.

A formação continuada pode ajudar no processo de ressignificação das teorias discutidas na formação inicial, mas é preciso estarmos atentos para o fato de que a formação continuada não é apenas prática. Mesmo quando se propõe a realizar a análise de atividades, planejamento de aulas, socialização de experiências, o que se quer é que possamos refletir sobre o que vivenciamos; o que se quer é teorizar a prática cotidiana e repensar a prática a partir dessa teorização. (BRASIL, 2015, p. 84)

Ainda em relação a instigarmos uma autoavaliação do programa como um todo, inquirimos os participantes acerca de como avaliavam sua estrutura. A avaliação pode ser conferida no gráfico 2 a seguir.

\section{Gráfico 2: respostas dos participantes referente à questão 04}
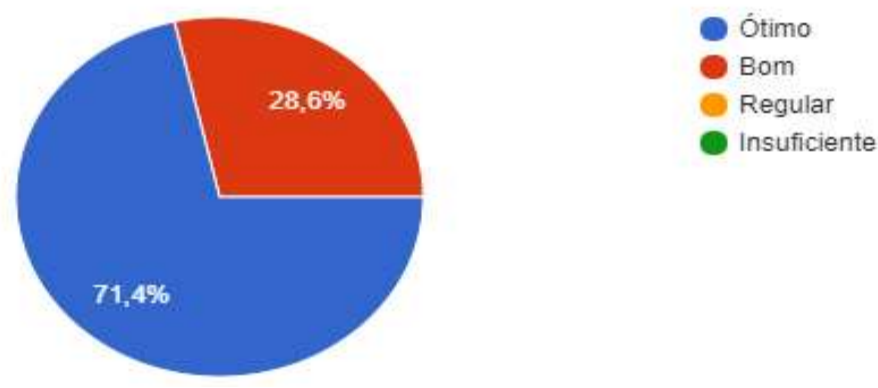

Relacionamos a avaliação realizada, ainda, para além da perspectiva da formação continuada, também, como importante mecanismo de atenção aos alfabetizadores envolvidos, de certo modo, com os processos de letramento, pois na contemporaneidade, tais processos assumem sua relevância no contexto educacional, sendo objeto e alvo de inúmeras pesquisas no campo escolar, conforme aponta a pesquisa realizada por Mortatti (2004, p. 95). 
Como podemos verificar, vem aumentando a produção acadêmica brasileira sobre o tema do letramento, buscando-se contemplar e explorar diferentes aspectos e problemas envolvidos no estudo do fenômeno, de diferentes perspectivas teóricas e metodológicas, especialmente no âmbito das ciências da educação e das ciências linguísticas. $O$ aumento dessa produção tem também evidenciado que, ao lado da diversidade de aspectos e abordagens, vem-se acumulando significativo conhecimento sobre o tema, que tende a ir-se constituindo como um corpo teórico e conceitual mínimo de referências comuns e intercambiáveis, que vêm, por sua vez, "formando opinião" dos interessados.

Nesse sentido, uma autoavaliação tão positiva do PNAIC se relaciona certamente ao potencial do programa em abordar a diversidade de aspectos e abordagens relacionados ao letramento e a alfabetização, como também, por estruturar sua atuação na multiplicidade de olhares e subjetividades envolvidas nas práticas docentes. A atuação do programa se faz complexa e variada, na medida em que se apresenta complexa a atuação docente nas diversas realidades. A partir dessa perspectiva, Mortatti, ainda, defende que:

Tais características obrigam a considerar a pluralidade do conceito de letramento, a fim de evitar a diluição das diferenças por meio de fórmulas simplificadoras que visem à fixidez e homogeneização do que é ainda provisório e heterogêneo, como fenômeno e como conhecimento em construção neste momento histórico. (MORTATTI, 2004, p. 95-96)

Instigamos os formadores a expressarem com suas palavras se consideravam que o Pacto ajudava os professores a se sentirem sensibilizados para repensar a atuação na escola, bem como, reformular as atividades, se adequando as reais necessidades propostas pelo programa. Conforme a tabela 3 a seguir:

Tabela 3: Respostas referentes a questão 06.

\begin{tabular}{|l|l|}
\hline Participante 1 & Sim. \\
\hline Participante 2 & $\begin{array}{l}\text { Sim, muito. Ajuda e incentiva a ter outro olhar, sob outra } \\
\text { perspectiva, respeitando a individualidade de todos os } \\
\text { sujeitos envolvidos no processo. }\end{array}$ \\
\hline Participante 3 & $\begin{array}{l}\text { Sim, mas é importante ressaltar os diferentes } \\
\text { encaminhamentos que foram gestados nos diferentes } \\
\text { âmbitos envolvidos no desenvolvimento do programa. }\end{array}$ \\
\hline Participante 4 & $\begin{array}{l}\text { Sim a proposta do PACTO foi excelente pois solicitava o } \\
\text { retorno das práticas, relato das atividades realizadas, } \\
\text { levando os educadores a reformular suas práticas. }\end{array}$ \\
\hline
\end{tabular}




\begin{tabular}{|l|l|}
\hline Participante 5 & Com certeza. \\
\hline Participante 6 & Sim. \\
\hline Participante 7 & $\begin{array}{l}\text { É, sem dúvida alguma, um dos poucos programas de } \\
\text { formação continuada para professores das séries iniciais que } \\
\text { realmente promove reformulações da prática docente. }\end{array}$ \\
\hline
\end{tabular}

As respostas dos formadores foram bem explícitas, demonstrando, com poucas palavras, o quanto foi importante participarem desse programa, e que o mesmo proporcionou aos profissionais terem uma nova perspectiva das suas práticas pedagógicas nos seus respectivos ambientes de trabalho, uma vez que esses trabalham com diferentes sujeitos. Um ponto que foi ressaltado por uma formadora foi que ocorreu o processo de solicitação das práticas aprendidas durante o programa, fazendo com que ocorresse uma reflexão acerca das práticas desenvolvidas pelos professores.

A última questão (07), tinha como seu objetivo saber quais foram as dificuldades encontradas pelos formadores para participarem do programa. As respostas foram variadas, mas bem objetivas, apenas duas formadoras não gostaram da localização na qual foi desenvolvido o programa. Conforme tabela 4 a seguir.

Tabela 4: Respostas referentes a questão 07.

\begin{tabular}{|l|l|}
\hline Participante 1 & Localização. \\
\hline Participante 2 & Não senti dificuldades. \\
\hline Participante 3 & $\begin{array}{l}\text { Construir uma diretriz convergente entre as diferentes } \\
\text { esferas organizacionais do programa. }\end{array}$ \\
\hline Participante 4 & $\begin{array}{l}\text { Na minha opinião todos os encontros foram facilitados pelo } \\
\text { programa sem dificuldades de participação. }\end{array}$ \\
\hline Participante 5 & $\begin{array}{l}\text { Como atuei como formadora, minha maior preocupação } \\
\text { sempre foi relativa a superar as expectativas dos } \\
\text { orientadores de estudo com as quais trabalhei nas } \\
\text { formações, pois sempre estavam buscando e querendo } \\
\text { conhecer mais e mais sobre os assuntos tratados. Isso exigiu } \\
\text { de mim muitas horas de estudo e preparo. }\end{array}$ \\
\hline Participante 6 & As reuniões em Santa Maria. \\
\hline
\end{tabular}




\begin{tabular}{|l|l|}
\hline Participante 7 & $\begin{array}{l}\text { Creio que o suporte nos municípios e escolas nem sempre é } \\
\text { ideal. Em geral, os pares que pactuam com o programa não } \\
\text { compreendem a importância do mesmo. }\end{array}$ \\
\hline
\end{tabular}

Os participantes como se pode observar em sua maioria demonstraram de uma forma bem sucinta que não sentiram muitas dificuldades ao participarem do programa, e mesmo quando estas aconteceram, não impactaram na qualidade do programa. No entanto, dentre as questões apresentadas aos formadores, esta é, certamente, a de maior importância para uma autoavaliação do programa, pois, permite conhecer os aspectos que necessitam de uma maior atenção. Tais como a concentração das atividades em uma única cidade e principalmente, investir na equidade de condições de trabalho entre os municípios e escolas. Como aponta um dos formadores, alguns profissionais envolvidos com as questões educacionais não compreendem a pertinência do programa e dessa forma não oferecem o suporte necessário às atividades.

\section{Considerações finais}

Através do presente estudos apresentou-se um breve panorama do Programa Pacto Nacional pela Alfabetização na ldade Certa (PNAIC), desde sua criação com destaque para as atividades e peculiaridades de suas ações no cenário nacional. Procurou-se através de um questionário semiestruturado conhecer alguns aspectos do PNAIC na visão dos professores formadores, a fim de construir uma autoavaliação das atividades desenvolvidas. Nesse sentido, os formadores avaliaram de forma bastante positiva sua participação e também o programa como um todo, destacando como aspectos fundamentais a completude do programa enquanto formação continuada.

Nesse sentido ainda, enfatizou-se a importância do PNAIC, na esfera educacional, devido a sua atuação junto aos professores dos anos iniciais da educação básica, comprometidos com a alfabetização e com o letramento. Para além disso, pode-se conhecer quais são as maiores dificuldades enfrentadas e percebidas 
pelos formadores, tais como a concentração das atividades de formação em uma única cidade e a falta de compreensão da relevância do programa por parte de outros professores.

Conclui-se que na visão dos formadores participantes da pesquisa o programa é bastante relevante e sua continuidade é considerada extremante positiva para 0 cenário nacional. No entanto, percebe-se que para uma avaliação, realmente completa, faz-se necessário conhecer também as percepções dos professores que atuam dentro do programa junto às escolas de Educação Básica, e deixa-se esta proposta como possível encaminhamento a ser realizado futuramente.

\section{Referências Bibliográficas}

BRASIL. Pacto Nacional pela Alfabetização na Idade Certa. Integrando Saberes. Caderno 10/ Ministério da Educação, Secretaria de Educação Básica. Brasília: MEC, SEB, 2015.

Resolução $\mathbf{n}^{\circ}$ 2: Define as Diretrizes Curriculares Nacionais para a formação inicial em nível superior. Brasília, 2015. Disponível em: http://pronacampo.mec.gov.br/images/pdf/res cne cp 02 03072015.pdf. Acesso em: 15 de Ago. de 2017.

Sobre a ANA. Disponível em: http://portal.inep.gov.br/educacaobasica/saeb/sobre-a-ana Acesso em: 18 de Ago. de 2017.

Pacto Nacional pela Alfabetização na Idade Certa. Disponível em: http://pacto.mec.gov.br/. Acesso em: 15 de Ago. de 2017.

Pacto Nacional pela Alfabetização na Idade Certa. Disponível em: http://coral.ufsm.br/pactonacional/index.php/sobre. Acesso em: 23 de Set. de 2017.

MORTATTI, Maria do Rosário Longo. Educação e Letramento. São Paulo: UNESP, 2004. 